\title{
On the electoral punishment/rewarding of the incumbent: \\ Can voters do it?
}

\section{Sobre a punição/recompensa eleitoral do incumbente: Podem os eleitores fazê-lo?}

\author{
António Bento Caleiro \\ University of Évora
}

\begin{abstract}
The article analyzes the possibility of voters penalizing or rewarding the incumbent (economic) performance at the polls. For this, it is considered that voters have limited rationality. This does not prevent them from performing this task without bias, which should serve as an obligation to use the elections to effectively penalize or reward the incumbent and/or not elect those who do not deserve it.
\end{abstract}

Keywords-Bounded rationality, Elections, Voters.

Resumo-O artigo analisa a possibilidade de os eleitores penalizarem, ou recompensarem, nas urnas, o desempenho (económico) do governo. Para tal, considera-se que os eleitores dispõem de racionalidade limitada. Tal não os impede de desempenharem aquela tarefa sem enviesamento, o que deveria servir de obrigação de utilização das eleições para, efectivamente, penalizar, ou recompensar, o governo e/ou não elegerem quem não o merece.

Palavras-Chave-Racionalidade Limitada, Eleições, Eleitores.

Submitted-28-09-2018. Accepted-06-02-2019.

\section{Introduction}

$\mathrm{T}$ HE electoral business cycles literature generally concludes that the short-run electorallyinduced fluctuations are harmful to the social

- António Bento Caleiro, Professor at the Department of Economy, University of Évora, Portugal.

E-mail: caleiro@uevora.pt

ORCID: https://orcid.org/0000-0003-1205-4404

DOI http://dx.doi.org/10.21814/perspectivas.335 welfare (in the long-run) $1^{1}$ As a matter of fact, because the electoral results depend on voters' evaluation, it can be said that the electorate is also responsible for existence of electoral business cycles as, through ignorance or for some other

1. In spite of the eminently theoretical content of the article, it is fair to refer to the vast amount of empirical studies that dealt with the verification of empirical support for the various models of electoral cycles: political or partisan; retrospective or rational. With regard to Portugal, Veiga and Veiga (2004) and Veiga and Veiga (2007) are two references of obvious interest. Eventually, Caleiro and Guerreiro (2004) is another, which shows that, in these matters, the use of spatial econometrics techniques is generally recommended. 
reason, allow them to exist.

A possible debate is then the one about the voters' rationality. What characteristics would distinguish rational from non-rational voters? These two types of voters should possess differing sets of knowledge and information concerning the workings of the economy. As their knowledge grows through learning, voters may approach full rationality. Consequently, the learning process voters go through should be of great importance. Given that, even with rational voters, electoral cycles can still exist, one should study the circumstances under which it would be desirable for a government to be facing fast-learning sophisticated voters, i.e. those voters who understand the constraints under which the government operates and thus will form their opinion on the basis of how closely actual performance adheres to the best within the possible. A competent but unfortunate government facing a particularly unpleasant evolution of exogenous conditions, for example, would be glad if voters learn quickly enough to distinguish between policy errors and simple bad luck.

Being even more impressive, in fact, an incumbent can be electorally punished by voters if it adopts socially optimal economic policies (Caleiro 2001). In this sense, if the objective is to remain in power to play the role of social welfare maximizer, the incumbent may face a dilemma: either it implements measures that are socially optimal and risk losing elections, or implements opportunist policies that are ultimately electorally awarded. Of course, this dilemma is sometimes exploited by incumbents whose (unique) aim is indeed to remain in power only to achieve private objectives. It is precisely these, and only these, incumbents who should be prevented from creating business cycles for electoral purposes (Caleiro 2018b).

This point introduces a well-known problem of electorally-induced behavior punishment.2 In fact, since McRae (1977) the possibility of a strategic voting on the part of the electorate was admitted, which would be to change, appropriately, the electoral preferences so that the incumbent is forced

2. Somehow related is the practice of monitoring the behavior of the incumbent throughout the mandate by the electorate. In reality, it seems that a constant monitoring of the incumbent seems not to be considered a crucial practice by the electorate. to implement the socially optimal economic policies, being rewarded, electorally by such. In other words, elections can in fact turn voters into the principal who has all the incentives to motivate the government, as the agent, to use the socially optimal policies (Caleiro 2004).

Elections are thus the appropriate mechanism (or moment in time) to punish or to reward the past behavior of the incumbent. That being true, it still remains the problem of being possible by the electorate to distinguish an opportunistic behavior from a benevolent one. This possibility, in turn, depends upon the information that is available and how it is processed by voters.

As is well-known, the first strand of electoral cycles models, considered adaptive expectations and retrospective voters (Nordhaus 1975; Hibbs 1977). The second generation of those models considered rational expectations as well as rational voters (Alesina 1987, 1988; Rogoff and Sibert 1988) ${ }^{3}$ Assuming this perspective, Minford (1995) is of relevance in the determination of those electoral punishment strategies.

Assuming rational expectations, in a situation where there are some stochastic shocks, it is optimal to let the government react to those shocks. But the allowance to use some discretion may not be used to try to exploit the Phillips curve, as (even the government should know) this attempt only results in unnecessary inflation. As Minford (1995) shows, there is the possibility of considering a discretionary electoral punishment large enough (that is an electoral defeat) to deter any attempt to exploit the Phillips curve, but no punishment at all for the correct response to shocks.

This absolute need to react only to shocks constitutes then a constraint in the government's optimization programme. This is so because it is in the government's own interest that the precommitment policy is shown to be computed in that way. Only in that circumstances the precommitment policies will be expected and effectively chosen because they are optimal. In this way, the government, by truly punishing itself if required to do so, will achieve a better outcome.

3. For an up-to-date review of the most recent developments in the electoral cycle literature, one may see Caleiro (2018a). 
See also Minford (1990).

As it is apparent that voters have good reasons for motivating the incumbent government, is it rational to expect that, despite the initial problems of making the punishment promises acquire credibility, these punishment strategies make sense? The infinite repetition of the gains from those strategies will plausibly overcome the costs. This is true in a rational expectations world, but we conjecture that it may be extrapolated to a bounded rationality world where, despite their limitations, voters that engage in a classification task, as illustrated in this chapter, can (may be not in a so fast or secure way than in the case just discussed) also motivate governments to act as a benevolent social-planner. ${ }^{4}$

In reality, it seems that voters often cannot truly judge/classify if an observed state/policy is the result of a self-interested/opportunistic government or, on the contrary, results as a socialplanner outcome, simply because voters do not know the structure/model/transmission mechanism connecting policy values to state values. In other words, it may be considered that voters are characterized by a bounded rationality.

The existence of bounded rationality in political matters, in general, and in electoral matters in particular, seems, in fact, to form the basis of a third generation of models. To prove this fact, Ashworth et al. (2018), Bendor (2010), Lee et al. (2016), Ogaki and Tanaka (2017) and Reed et al. (2018), are (quite) recent references of undeniable interest, which support this.

Bounded rationality voters were already considered in Caleiro (2001, 2013), performing a classification task by the use of a neural network $5^{5}$ As was clear, neural networks performed the classification task, i.e. made the 'division' between opportunistic and benevolent policies, learning the relationships between the relevant variables in a model-free way. ${ }^{6}$

4. As is well known, the bounded rationality approach is immediately associated with the works of Herbert Simon. See, for instance, Simon (1982). See also Wall (1993).

5. See for a general approach on how neural networks can be applied see Swingler (1996).

6. This model-free approach gives enough flexibility to obtain good performances at finding relationships in an input-output space even, if the space is complex and the patterns between inputs and outputs are ill defined.
A possible shortcoming of Caleiro (2001, 2013) is, indeed, the lack of uncertainty that is considered when the classification task is being performed. Naturally, when some 'noise' is present, the classification task becomes more difficult. In this article we thus want to extend the previous analysis by the consideration of uncertainty.

That being said, the remainder of the article is structured as follows: Section 2 offers a general discussion of bounded rationality (voters); Section 3 considers this kind of voters whose objective is to compute the benevolent component in the economic policy of the incumbent (in order to punish or reward, at the elections the incumbent); Section 4 concludes.

\section{On Bounded Rationality Voters}

"In the

spirit of the bounded rationality research program, which is really to put the economist and the agents in his model on an equal behavioral footing, we expect that, in searching these literatures for ways to model our agents, we shall find ways to improve ourselves." in Sargent (1993, 33)

\subsection{A technical note}

In methodological terms, this section considers a bounded rationality approach, where the differences between different types of learning (for instance, adaptive or procedural) must be taken into account.

Generally speaking, learning models have been developed as a reasonable alternative to the unrealistic informational assumption of rational expectations models. Moreover, through learning models it is possible to study the dynamics of adjustment between equilibria which, in most rational expectations models, is ignored. In fact, rational expectations hypotheses are, in some sense and with some exceptions, a limiting property of a dynamic system which evolves from one equilibrium to another, this being possible because it is assumed that agents know the true model of the economy and use it to form their expectations which, in turn, implies that agents are also able to solve the model.

Interestingly, learning models also deal with another difficulty of rational expectations models, 
namely the existence of multiple equilibria. 7 It is well known that for linear models, where only expectations of current variables are considered, the rational expectations equilibrium is unique. On the other hand, when expectations about the future endogenous variables are required, multiple rational expectations equilibria can occur. Moreover, this is also a common feature of stochastic control/decision problems. In this case, the lack of equilibrium uniqueness arises from an imperfectly specified intertemporal decision problem under uncertainty.

The analysis of learning processes can, in fact, provide a way of selecting the 'reasonable' equilibrium or sub-set of equilibria. On the one hand, if the learning mechanism is chosen optimally, then a desirable rational equilibrium is selected from the set of the rational expectations equilibria; see Marcet and Sargent (1988, 1989a, 1989b). On the other hand, if the learning mechanism is viewed under an adaptive approach, in particular in expectational stability models, it can also act as a selection criterion in multiple equilibria models involving 'bubbles' and 'sunspots'; see Evans (1986), Evans and Guesnerie (1992), Evans and Honkapohja $(1990,1992,1999)$. To sum up, learning mechanisms, whether optimally or adaptively chosen, 'select' the particular steady state as, in some sense, terminal conditions do (Minford et al. 1979).

Through this last point, one can already anticipate the usual distinction between learning mechanisms. Although a number of different studies modelling learning have been presented, two main classes of models can be distinguished: rational learning and boundedly rational learning models ${ }^{8}$ In rational learning models, it is assumed that agents know the true structural form of the model generating the economy, but not some of the parameters of that model. In boundedly rational learning models, it is assumed that agents, while

7. For a seminal approach on sunspots and multiple equilibria see Farmer (1999).

8. Westaway (1992) prefers to distinguish closed-loop learning, where agents learn about the parameters of the decision rule, from open-loop learning, where agents form an expectation of the path for a particular variable which they sequentially update. As is pointed out, closed-loop learning will be virtually identical to the parameter updating scheme using Kalman filtering. learning is taking place, use a 'reasonable' rule, for instance, by considering the reduced form of the model.

Rational learning, which some authors identify with Bayesian learning, thus assumes that the model structure is known by the agents while the learning process is taking place. Given the difficulties that arise in modelling this kind of learning, the bounded rationality approach has the appealing advantage of being (at least) more tractable. Moreover, the assumption that agents use a mis-specified model during the learning process makes the bounded rationality approach less controversial.

Obviously, the use of a mis-specified model during learning has its consequences on the formation of expectations. In fact, under the bounded rationality approach, agents are modelled as using an 'incorrect' rule, derived from backward-looking reduced form equations, to generate expectations while they are learning about the true structural form.

In the bounded rationality approach, various notions of expectational stability and of econometric learning procedures have been the main formulations. Interestingly, the distinction between these two main procedures has to do with the 'notion' of time where learning takes place. While the expectational stability principle assumes that learning takes place in 'notional', 'virtual' or meta-time, econometric learning procedures assume real-time learning.

The expectational stability approach considers the influence of - and thus the distinction between - perceived laws on actual laws of motion of the economic system. The actual law of motion results from the substitution of the perceived law of motion in the structural equations of the true model. It is then possible to obtain a mapping $\mathrm{L}(\Theta)$ from the perceived to the actual law of motion, where $\Theta$ denotes the set of parameters. Rational expectations solutions $\bar{\Theta}$ are then the fixed points of $\mathrm{L}(\Theta)$. 
Finally, a given rational expectations solution $\bar{\Theta}$ is said to be expectationally-stable if the differential equation

$$
\frac{d \theta}{d \tau}=L(\theta)-\theta
$$

is locally asymptotically stable at $\bar{\Theta}$, where $\tau$ denotes meta-time.

In adaptive real-time learning, agents are assumed to use an econometric procedure for estimating the perceived law of motion. Least-squares learning is widely used in this formulation in spite of its apparent drawbacks; see Salmon (1995) for a criticism of this issue. A more sophisticated application of these econometric procedures is the consideration of the Kalman filter which, as is well known, nests least squares learning and recursive least squares. $?^{9}$

\subsection{On learning voters}

The biggest lesson to be drawn from the previous subsection is that whatever the form of learning (on the part of the voters), their behavior will always be different from that assumed, whether they be retrospective or rational. This difference is fundamental and must be taken into account by the incumbent, who may naturally wish to be electorally rewarded or, in other words, not to be electorally penalized. In addition, voter learning is also critical to the incumbent's acquisition of credibility or reputation throughout the mandate.

Although the analysis of credibility and reputation does not relate directly to the idea of electorally-induced policy decisions, there are close associations to the implications of a bounded rationality electorate. If voters do have rational expectations, then they will be aware of the timeinconsistency problem and 'punish' the government by withdrawing belief in policy announcements and/or electoral support for a government who is trying to obtain short-run benefits from time inconsistent announcements.

9. If agents never discount past information, then Kalman filtering can be seen as a rolling least-squares regression with an increasing sample. On the contrary, if past information becomes less important, then a 'forgetting factor' can be included which gives a rolling window, or more precisely a form of weighted least squares.
To clarify the connection between these last two issues, one should refer to Barro and Gordon (1983). These authors identify two particular problems with the analysis of time consistent policies and reputational equilibria. Firstly, that the equilibrium is not unique. The second problem is that policy-makers are assumed to have an infinite time horizon. It is obviously hard to accept an infinite horizon assumption when policy-makers are periodically subject to elections 10 A method of tackling this problem was introduced by authors like Backus and Driffill (1985a,1985b), i.e, to suppose that economic agents are unsure of what the actual objectives of the policy-maker are. The introduction of uncertainty about policy-makers' objectives leads to some confusion about what policymakers are trying to achieve, and hence agents (voters) have to learn about policy-makers' intentions.

Given the above discussion we can then question, as Westaway (1992) clearly and naturally points out: "How do policymakers react to the fact that the private sector is learning?".

Paradoxically, this pertinent question has been almost ignored. In fact, the analysis of the implications of learning mechanisms in policy-making is far from being complete, still nowadays. Some exceptions are Barrell et al. (1992), Basar and Salmon (1990a, 1990b), Cripps (1991), Evans and Honkapohja (1993), Fuhrer and Hooker (1993), Marimon and Sunder (1993, 1994), Salmon (1995) and Westaway (1992).

Salmon (1995) is, to the best of my knowledge, the only reference where an innovative bounded rationality approach such as neural networks learning has been applied in a policymaking problem.11 We propose to use this approach within an electoral business cycles context 12

10. However, as Persson and Tabellini (1990, 42) argue, an infinite horizon is acceptable when the final period of the game is random and/or players are viewed as collective bodies of overlapping generations' individuals.

11. See White (1989) for an analysis of some asymptotic results for learning in single hidden-layer feedforward network models

12. In Caleiro $(2001,2013)$ it was already considered that bounded rationality voters have to (crisply) classify economic policies as coming from opportunistic or benevolent government behavior. 
That said, the following section will consider that bounded rationality voters have to (crisply) classify economic policies as coming from opportunistic or benevolent government behavior.

\subsection{An Approximation of Economic Policies Example}

This section will consider a signal extraction problem faced by the public. Others have treated this problem before; see, in particular, Basar and Salmon (1990b) and Cripps (1991) following the initial study of Cukierman and Meltzer (1986) 13 The novelty considered in our case is, naturally, the use of neural networks.

Most of the electoral cycle literature on these matters discusses the situation where there is absolutely no uncertainty. If this is the case, then in some sense, the strategic voting, as described for instance in MacRae (1977), can be more safely or more fairly performed. To be clearer, this is to say that, because there are no stochastic elements 'contaminating' the effects of economic policies on economic outcomes, then punishing 'wrong' outcomes should be as easy, or as fair, as punishing 'wrong' policies. Alternatively, the motivation needed to obtain 'good' outcomes may be as well be done at the economic policy level. Obviously, when the results of the economic policies also depend upon the realization of, say, stochastic shocks, a sophisticated electorate may want to consider it safer or fairer to punish or monitor policies rather than outcomes.

Let us then consider that the incumbent uses some policy instrument, $\chi$, to influence the behavior of some state variable, $y$, which voters consider to be decisive for their voting decisions. ${ }^{14}$ Furthermore, the state variable y is also influenced by some random shocks, $s$ as follows:

13. In these papers it is considered that the government has a noisy control of the money supply growth given that the planned money supply growth, $m_{t}^{p}$, in the role of policy instrument, is affected by a (normally distributed) random shock $\varepsilon_{t}$, such that the actual rate of money supply growth, $m_{t}$, is given by $m_{t}=$ $m_{t}^{p}+\varepsilon_{t}$

14. To keep the approach as general as possible, we prefer not to restrict ourselves to a specific control variable $\chi$ and/or a specific state variable y. In this sense, the model considered in Caleiro (2001) can, after some simple transformations, be viewed as a particular case of this general model.

$$
y=x+\theta s
$$

where $\Theta$ is some distortion factor and $\mathrm{s}$ $N\left(\bar{s}, \sigma_{s}^{2}\right)$.

The information that $y$ is influenced by $x$ and $\mathrm{s}$ is assumed to be available to both incumbent and voters, but an asymmetry of information is considered in the sense that, while the incumbent knows the value of the distortion factor $\Theta$, this does not happen with voters. Moreover, it is assumed that shocks are observed, by voters and by the incumbent, only after the policy has been implemented.

The programme for the incumbent is, then, to determine its policy in order to

$$
\min _{x} E\left[(y-\tilde{y})^{2}\right],
$$

where $\tilde{y}$ is the first-best value for voters.

The solution of (2) subject to (1) is, as the certainty equivalence principle would prescribe:

$$
\tilde{x}=\tilde{y}-\theta s .
$$

Voters face a different problem. They consider it important to know in what proportion the evolution of relevant variables can be attributed to the incumbent's economic policy itself. In fact, and for instance, a 'negative' evolution of the economy can be 'excused' by voters if they perceive this evolution as being essentially the result of a bad conjugation of shocks. In this case, the incumbent would certainly benefit from sophisticated voters, i.e. those who try, through a learning process, to understand the constraints under which incumbent acts.15

To sum up, the electorate will judge incumbent's performance after taking into account, i.e., subtracting the effect of shocks, $s$, on the state variable $y$. Because voters do not know the way shocks affect the state variable, that is, ignore the

15. On the other hand, (incompetent) incumbents can, of course, take benefit from the ignorance of voters. 
value of $\Theta$, they cannot themselves determine the solution (3).

For the above problem, a special kind of neural network is appropriated. These are usually known as adaptive neural networks. This kind of neural network contrasts with that considered in Caleiro (2001), because while perceptron training mechanism adjusts weights and bias in each epoch. 16 based on all training elements at once, in adaptive neural networks, learning is done on a continuous basis of time, which agrees more with this particular problem that has to be solved by voters 17

To recapitulate, voters observe the input $\mathrm{s}$ and the output $\mathrm{y}$ and have to extract from $\mathrm{y}$ the contribution that is due to the economic policy, that is, $x$. This can be done by the analysis of the error committed by the adaptive network. Because the neural network output signal will match $y$ as best as it can, then, considering $s$ as the only input, the neural network will determine the optimal prediction $y^{p r}=\Theta^{p r} s$. The neural network error will then be $y-y^{p r}$, that being exactly the estimated value of $x$.

Let us consider a simple example ${ }^{18}$ From (3) we obtain that, for an optimal state value $\tilde{y}=$ 0.75 , a distortion factor of $\theta=1.5$ and the mean value of shocks $\bar{s}=0.1$, the optimal policy will be $\tilde{x}=0.6$. Considering a random sample for the shocks, as the input, and the mentioned value for $x$, we can then obtain the actual output y from (1). The adaptive neural network estimates, from these inputs and outputs, the contribution of the policy to be as depicted in Figure 1.

16. An epoch is the unit of time where learning takes place. Hence, a new epoch corresponds to an update of the parameters.

17. This means that we can consider that both dimensions of time can be present and therefore both kind of learning can be considered.

18. This task was performed using the neural networks toolbox in MATLAB.

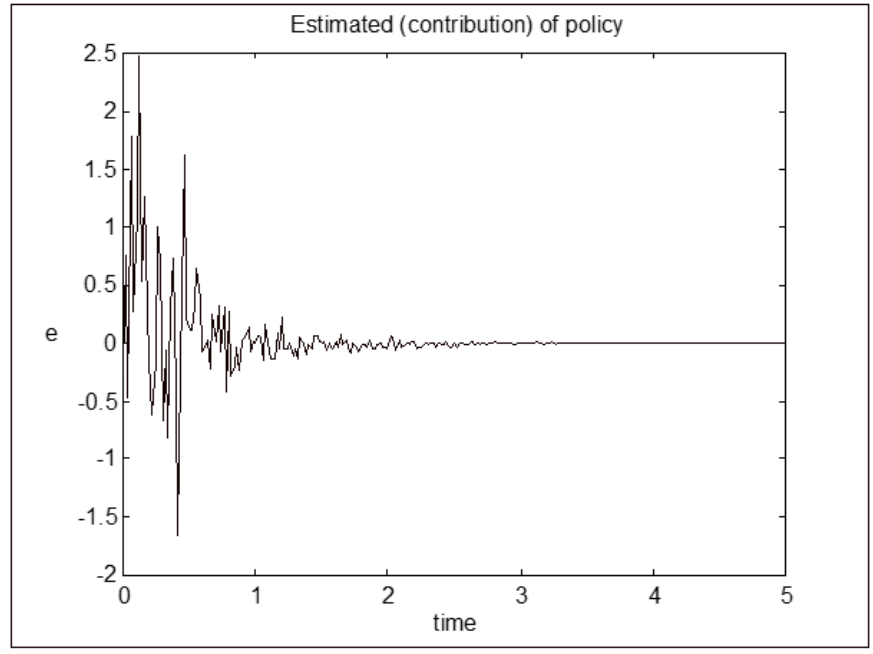

Figure 1: A constant policy

From an inspection to Figure 1, it is clear that, after some adjustment period, the optimal performance of the network gives us a perfect match between actual and estimated outputs. As explained before, this result will mean that the constant policy $x=0.6$ effect is totally 'absorbed' by an over-estimation of the distortion factor $\theta$. To sum up, voters would consider that incumbent did not contribute at all to the actual evolution of the state variable 19

What if the incumbent follows the policy rule (3), but the actual policy is disturbed by some random shock such that $x=x^{p}+\varepsilon$ where $x^{p}$ is given by (3) and $\varepsilon$ is a (normally distributed) random shock, as is considered in Cukierman and Meltzer (1986), Basar and Salmon (1990b) and Cripps (1991)? The results change as Figure 2 illustrates.

The network still makes an error as concerns the contribution of the economic policy, but it no longer assumes a zero contribution of policy - after the adjustment period - although on average this is true. As Figure 2 shows, on average the error concerning the contribution of policy is 0.6 , exactly the value that the incumbent is implementing. Hence, in some sense, when the policy is disturbed by some shock, that provides information allowing a different judgement to be made of its contribution to the evolution of $y$.

To end up, one can be curious about the performance of the network when the incumbent implements a completely random policy.

19. A neural network without the additive bias was also considered. The results did not change in a significant way. 


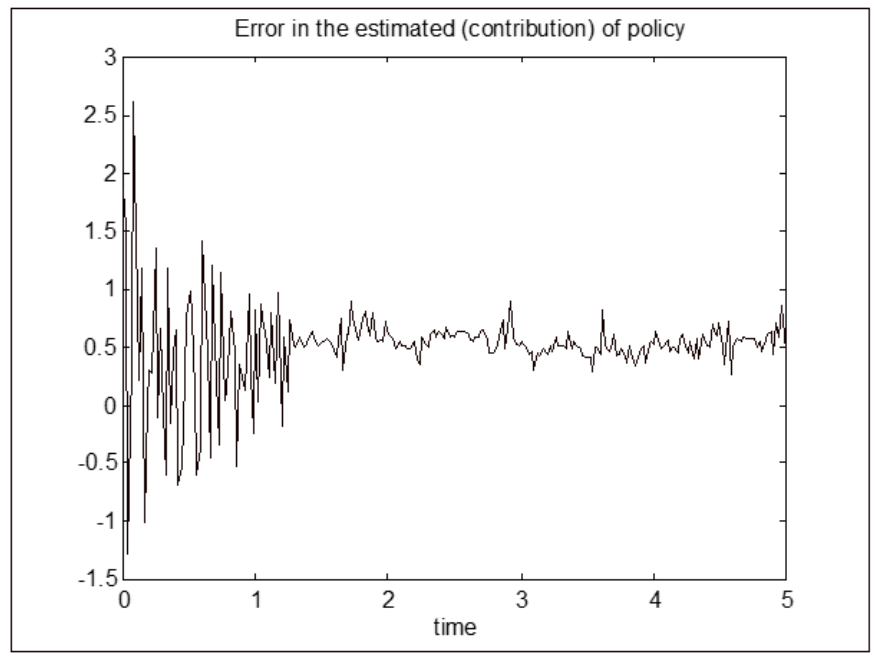

Figure 2: A disturbed policy

At first sight, this seems to be the most difficult/challenging situation to be handled by voters. In fact, it is not. The variation in $x$ provides enough information to better estimate the contribution of the economic policy, and the absence of constant behavior invalidates its absorption by the contribution of shocks. Consider, then that $x$ is just a drawing of a normal distribution. The results are shown in Figure 3.

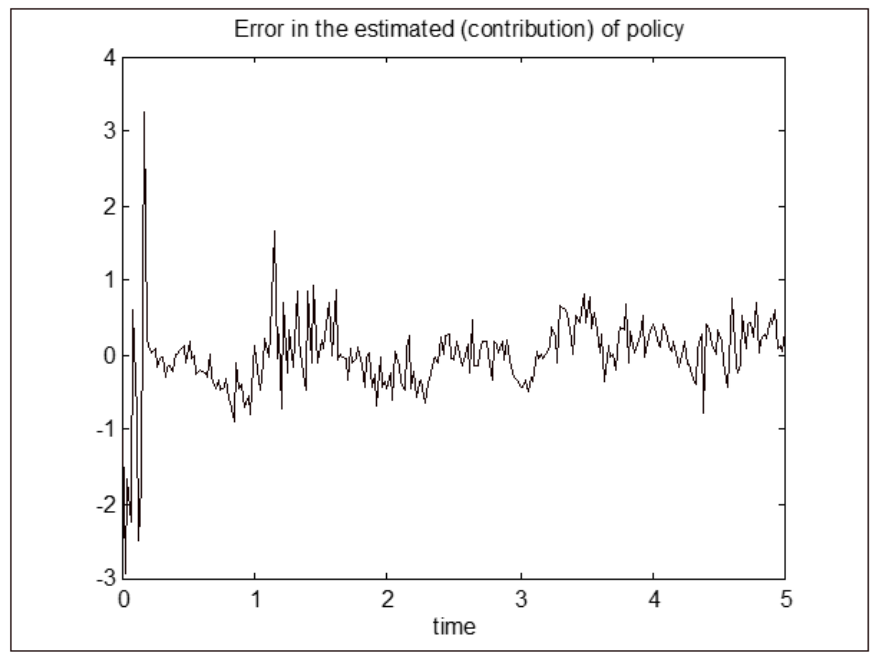

Figure 3: A random policy

Plainly, although not in a perfect way, voters would, on average, approximate the economic policy $x$ contribution to the evolution of their relevant state variable $y$.

\section{Conclusion}

The question of an electoral cycle created by the incumbents is often associated with democracy. This debate motivates an interest in the relationship between economic policy and political or electoral issues. In particular, the following conjectures have been central to the debate:

1) Greater evidence of an electoral cycle is usually drawn from observing stable governments which 'benefit' from ruling throughout sufficiently long mandates;

2) The commitment implicit in the coordination of policies which results from economic integration creates substantial difficulties for the manipulation of economic policy for electoral purposes;

3) The more information that is available to the electorate the harder it becomes to manipulate economic policy for electoral purposes.

Since the very first studies on electoral cycles, some authors offered suggestions as to what should be done against this electorally-induced instability. In fact, a good alternative to the proposal to increase the electoral period length 20 is to consider that voters stop being passively naive and, instead, are willing to learn about incumbent's intentions. This is the suggestion of some authors such as Nordhaus (1975), Frey (1978), Neck (1991), and Detken and Gärtner (1992).

Plainly, to verify the robustness of this presumption is of relevance. In fact, the economics literature has so far not paid the deserved attention to the importance of voters' behavior at the polls in what concerns punishment/rewarding strategies, and, to the best of my knowledge, almost no research has been done on boundedly rational voters.

Therefore in this article it was called attention to the importance that voters have in the possibility of creating a business cycle intended (only) to make the party in power win the forthcoming election. A priori, one may think as Rogoff and Sibert $(1988,1)$, pointed out that:

20. There is, in fact, some empirical evidence showing that the longer the electoral term, the less likely it is for the political business cycle to occur; see Soh (1986). Yet, Paldam (1979)'s results are, in a sense, contrary to this empirical evidence. 
"As long as private agents (such as wage setters) understand the government's incentives, one would not expect to observe any systematic rise in employment prior to the elections. But the objections to conventional political business cycle models go beyond their Phillips curve formulation, and apply to any model in which the government takes artificial measures to make itself look good."

It is then apparent that it remains in the hands of voters to prevent governments having incentives to take those kinds of artificial measures. To put it differently, voters indeed should motivate the government to choose policies that are optimal from the society's point of view instead of those that simply maximize popularity or that, for example, try to exploit the Phillips curve. That objective seems difficult to achieve when voters do not engage in a constant monitoring of government actions. If so, voters can signal their discontentment on the election day. An eventual punishment is then only given on that day. In fact, as Minford (1995) points out, the elections are an excellent mechanism to punish any attempt to, using the same example, exploit the Phillips curve. Rational voters can in this way motivate the government to choose the right policies.

Given the obvious importance of electoral punishment/rewarding strategies for the inexistence (existence) of electoral cycles, the article explored the implications of these strategies as sensible motivation for incumbents to choose the optimal (social) economic policies. To do this, the usual assumption of totally rational voters was abandoned and substituted by bounded rationality voters, which seems to be more reasonable. In particular, these voters were supposed to use a neural network reasoning to decide whether to reward or to punish the economic policies of the incumbent. As it was shown, being bounded in its rationality, that does not prevent the electorate from performing this task without bias, which should serve as an obligation to use the elections to effectively penalize or reward the incumbent and/or not elect those who do not deserve it.

Admittedly, the neural network application was not the result of camouflaging difficulties. Although the performance of neural networks as a bounded rationality way of learning was not completely satisfactory, this must be viewed as an incentive to continue and not to give up. As previously pointed out, although it seems important or crucial to consider the effects of learning on voters' behavior, the fact is that this issue has been largely ignored in the literature.

The great flexibility of neural networks sometimes poses the problem of their being used as 'black-boxes'. In fact, one might be interested in conditioning how neural network decisions/results are derived and, in particular, interested in being able to 'interfere' in those results. An alternative is provided by fuzzy logic, because it allows for the inclusion of rules provided by agents and is capable of explaining the decisions obtained.

Interestingly, one can consider that agents using fuzzy logic reasoning also see their rationality bounded. In this sense, there are close relations between neural networks and fuzzy logic; see, among others, Deboeck (1994) and/or Chen (1996). From a formal point of view, this close connection is supposed to be a promising basis for future research.

Other avenues for further research may as well be to: a) consider heterogeneous agents (with bounded rationality), following the approach of Rios-Rull (1997), by generalizing the, so called Harmington aggregator procedure; b) consider ergodicity across time, allowing for the determination of fixed points with homogenous and heterogeneous agents with and without bounded rationality; c) bridging the approach to irrational behavior and herding in finance (Shiller 2003).

\section{References}

[1] Alesina, Alberto. 1987. "Macroeconomic Policy in a TwoParty System as a Repeated Game." The Quarterly Journal of Economics CII: 651-678.

[2] Alesina, Alberto. 1988. "Credibility and Policy Convergence in a Two-Party System with Rational Voters." The American Economic Review 78(4): 796-805.

[3] Ashworth, Scott, Ethan Bueno de Mesquita, and Amanda Friedenberg. 2018. "Learning about voter rationality." American Journal of Political Science 62(1): 37-54.

[4] Backus, David, and John Driffill. 1985a. "Rational Expectations and Policy Credibility Following a Change in Regime." The Review of Economic Studies 52(2): 211-222.

[5] Backus, David, and John Driffill. 1985b. "Inflation and Reputation." The American Economic Review 75: 530-538.

[6] Barrell, Ray, Guglielmo Maria Caporal, Stephen Hall, and Anthony Garratt. 1992. "Learning about Monetary Union: An Analysis of Boundedly Rational Learning in European Labour Markets." Discussion Paper No. 22, August, National Institute of Economic and Social Research. 
[7] Barro, Robert J., and David B. Gordon. 1983. "Rules, Discretion, and Reputation in a Model of Monetary Policy." Journal of Monetary Economics 12: 101-122.

[8] Basar, Tamer, and Mark H. Salmon. 1990a. "Inflation and the Evolution of the Credibility with Disparate Beliefs". In Dynamic Modelling and Control of National Economies 1989: Selected papers from the 6th IFAC Symposium, edited by Nikos M. Christodoulakis, 75-81. Oxford: Pergamon Press.

[9] Basar, Tamer, and Mark H. Salmon. 1990b. "Credibility and the Value of Information Transmission in a Model of Monetary Policy and Inflation." Journal of Economic Dynamics and Control 14: 97-116.

[10] Bendor, Jonathan. 2010. Bounded Rationality and Politics. Oakland (CA): University of California Press.

[11] Chen, C.H. (ed.). 1996. Fuzzy Logic and Neural Network Handbook. New York: McGraw-Hill.

[12] Caleiro, António. 2001. "Essays on Election Dates, Economic Policies and Voters." PhD. diss., European University Institute.

[13] Caleiro, António. 2004. "Economic Policies and Elections: A principal-agent point of view." Notas Económicas 20: 89101.

[14] Caleiro, António, and Gertrudes Guerreiro. 2005. "Understanding the Election Results in Portugal: A spatial econometrics point of view." Portuguese Economic Journal 4(3): 207-228.

[15] Caleiro, António. 2013. "How to Classify a Government: Can a perceptron do it?" International Journal of Latest Trends in Finance and Economic Sciences 3(3): 523-529.

[16] Caleiro, António. 2018a. "From Specific to General in Electoral Cycle Models." Perspectivas - Journal of Political Science 19: 51-63.

[17] Caleiro, António. 2018b. Should electoral cycles disappear? Research Proposal. (available at: http://doi.org/10.13140/ RG.2.2.27086.10561)

[18] Cripps, Martin. 1991. "Learning Rational Expectations in a Policy Game." Journal of Economic Dynamics and Control 15: 297-315.

[19] Cukierman, Alex, and Allan H. Meltzer. 1986. "A theory of ambiguity, credibility, and inflation under discretion and asymmetric information." Econometrica 54(5): 1099-1128.

[20] Deboeck, Guido J. 1994. Trading on the Edge: Neural, Genetic, and Fuzzy Systems for Chaotic Financial Markets. New York: John Wiley Sons.

[21] Detken, Carsten, and Manfred Gärtner. 1992. "Governments, trade unions and the macroeconomy: An expository analysis of the political business cycle." Public Choice 73: 37-53.

[22] Evans, George. 1986. "Selection Criteria for Models with Non-uniqueness." Journal of Monetary Economics 18: 147157.

[23] Evans, George W., and Roger Guesnerie. 1992. Rationalizability, Strong Rationality and Expectational Stability. Discussion Paper No. TE/92/237. London School of Economics.

[24] Evans, George W., and Seppo Honkapohja. 1990. Learning, Convergence, and Stability with Multiple Rational Expectations Equilibria. Discussion Paper No. TE/90/212. London School of Economics.

[25] Evans, George W., and Seppo Honkapohja. 1992. Adaptive Learning and Expectational Stability: An Introduction. Discussion Paper No. TE/92/248. London School of Economics.

[26] Evans, George W., and Seppo Honkapohja. 1993. "Learn- ing and Economic Fluctuations: Using Fiscal Policy to Steer Expectations." European Economic Review 37: 595-602.

[27] Evans, George W., and Seppo Honkapohja. 1999. "Learning Dynamics". In Handbook of Macroeconomics, edited by John B. Taylor and Michael Woodford, 449-542. Amsterdam: Elsevier Science.

[28] Farmer, R. E. (1999). The macroeconomics of self-fulfilling prophecies. MIT Press.

[29] Fuhrer, Jeffrey C., and Mark A. Hooker. 1993. "Learning about Monetary Regime Shifts in an Overlapping Wage Contract Model." Journal of Economic Dynamics and Control 17(4): 531-553.

[30] Hibbs Jr., Douglas. 1977. "Political Parties and Macroeconomic Policy." The American Political Science Review 71: 1467-1487.

[31] Lee, I-Ching, Eva E. Chen, Chia-Hung Tsai, Nai-Shing Yen, Arbee L. P. Chen, and Wei-Chieh Lin. 2016. "Voting intention and choices: Are voters always rational and deliberative?" PloS one 11(2).

[32] MacRae, C. Duncan. 1977. "A Political Model of the Business Cycle." The Journal of Political Economy 85(2): 239-263.

[33] Marcet, Albert, and Thomas J. Sargent. 1988. "The Fate of Systems with 'Adaptive' Expectations." The American Economic Review 78(2): 168-172.

[34] Marcet, Albert, and Thomas J. Sargent. 1989a. "Convergence of Least Squares Learning Mechanisms in SelfReferential Linear Stochastic Models." Journal of Economic Theory 48(2): 337-368.

[35] Marcet, Albert, and Thomas J. Sargent. 1989b. "Convergence of Least-Squares Learning in Environments with Hidden State Variables and Private Information." Journal of Political Economy 97(6): 1306-1322.

[36] Marimon, Ramon, and Shyam Sunder. 1993. "Indeterminacy of Equilibria in a Hyperinflationary World: Experimental Evidence." Econometrica 61(5): 1073-1108.

[37] Marimon, Ramon, and Shyam Sunder. 1994. "Expectations and Learning under Alternative Monetary Regimes: An Experimental Approach." Economic Theory 4: 131-162.

[38] Minford, Patrick, Kent Matthews, and Satwant Marwaha (1979). "Terminal Conditions as a Means of Ensuring Unique Solutions for Rational Expectations Models with Forward Expectations." Economics Letters 4(2): 117-120.

[39] Minford, Patrick. 1990. "Ulysses and the Sirens: A Political Model of Credibility in an Open Economy". In Private Behaviour and Government Policy in Interdependent Economies, edited by Anthony S. Courakis and Mark P. Taylor, 337-355. Oxford: Oxford University Press.

[40] Minford, Patrick. 1995. "Time-Inconsistency, Democracy, and Optimal Contingent Rules." Oxford Economic Papers 47(2): 195-210.

[41] Nordhaus, William. 1975. "The Political Business Cycle." The Review of Economic Studies 42(2): 169-190.

[42] Ogaki, Masao, and Saori Tanaka. 2017. "Bounded Rationality." In Behavioral Economics, edited by Masao Ogaki and Saori Tanaka, 71-82. Singapore: Springer.

[43] Paldam, Martin. 1979. "Is There an Electional Cycle? A Comparative Study of National Accounts." Scandinavian Journal of Economics 81(2): 323-342.

[44] Persson, Torsten, and Guido Tabellini. 1990. Macroeconomic Policy, Credibility and Politics. London: Harwood Academic Publishers.

[45] Reed, Ryan, Craig Curtis, and Nicholas P. Lovrich Jr. 2018. "Does Democracy Entail an Obligation to Make Rational Policy Decisions? The Muddling Through vs. 
Bounded Rationality Debate Through a Lockean and Madisonian Lens." Public Integrity: 1-14.

[46] Rios-Rull, José-Victor. (1997). Computation of equilibria in heterogeneous agent models. Staff Report 231, Federal Reserve Bank of Minneapolis.

[47] Rogoff, Kenneth, and Anne Sibert. 1988. "Elections and Macroeconomic Policy Cycles." The Review of Economic Studies 55(1): 1-16.

[48] Salmon, Mark. 1995. "Bounded Rationality and Learning: Procedural Learning". In Learning and Rationality in Economics, edited by Alan Kirman and Mark Salmon, 236-275. Oxford UK Cambridge USA: Blackwell.

[49] Sargent, Thomas. 1993. Bounded Rationality in Macroeconomics. Oxford: Clarendon Press.

[50] Shiller, Robert J. 2003. "From efficient markets theory to behavioral finance." Journal of Economic Perspectives 17(1): 83-104.

[51] Simon, Herbert. 1982. Models of Bounded Rationality. Cambridge, MA: MIT Press.

[52] Soh, Byung Hee. 1986. "Political Business Cycles in Industrialized Democratic Countries." Kyklos 39(1): 31-46.

[53] Swingler, Kevin. 1996. Applying Neural Networks: A Practical Guide. London: Academic Press Limited.

[54] Veiga, Francisco José, and Linda Gonçalves Veiga. 2004. "The Determinants of Vote Intentions in Portugal." Public Choice 118(3-4): 341-364.

[55] Veiga, Linda Gonçalves, and Francisco José Veiga. 2007. "Political business cycles at the municipal level." Public Choice 131(1-2): 45-64.

[56] Wall, Kent. 1993. A Model of Decision Making Under Bounded Rationality. Journal of Economic Behavior and Organization 20: 331-352.

[57] Westaway, Peter. 1992. "A Forward-Looking Approach to Learning in Macroeconomic Models." National Institute Economic Review 2: 86-97.

[58] White, Halbert. 1989. "Some Asymptotic Results for Learning in Single Hidden-Layer Feedforward Network Models." Journal of the American Statistical Association 84(408) 1003-1013.

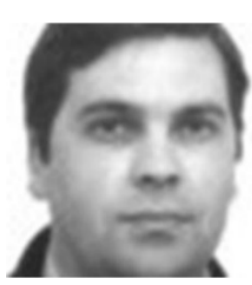

António Bento Caleiro holds a bachelor's degree in economics from the University of Évora, a master's degree in applied mathematics for economics and management by the Instituto Superior de Economia e Gestão (Lisbon) and a doctorate in economics from the European University Institute (Florence). Since May 2001, he has been an Assistant Professor at the University of Évora, having taken part in the Economics Unit at the University of Évora in March 2011. His research interests are (evidently) of a multidisciplinary nature, as the present work illustrates. 